\title{
An Essay on Memory, Identity and Aesthetics Embodied in Traditional Material Culture of Polish Spisz ${ }^{1}$
}

\begin{abstract}
The presented article concerns a change in the function and importance of the material elements of traditional folk culture in Polish Spisz (southern Poland). Older, usually wooden handicrafts related to farming (carts, cart wheels, ploughs, harrows, troughs, benches, etc.) have already lost their original functions in the highly modernised environment and are now used as aesthetic historical objects, hung on the walls of new buildings or placed in one's garden by the house. At the same time, they become part of a wider project of garden aesthetics by being placed alongside popular elements such as flower beds, water features, plastic or plaster garden gnomes and farm animals, which serve as mementos of a bygone culture. The museum-like expositions of these remainders also suggest that the nature of cultural memory has changed from "true memory" (unreflective, authoritative) into "historical memory" (reflective, discoursive). They become part of displays of memory and cultural heritage that expresses the transvaluation of the obsolete. As unique material mythemes, they form a tale connecting the cultural past with the present, a narration that is understandable for its inheritors, and quality objects that are included in cultural change and thus uphold a feeling of homefulness. This makes the entire process of cultural modernisation, from which the discussed material elements of traditional folk culture have not been totally removed, relatively gentle and gradual.
\end{abstract}

Keywords: aesthetics, tradition, material culture, memory, rusticity, Polish Spisz.

1 This project was financed by the Polish National Science Center, Poland, under decision no. DEC-2013/09/B/HS 3/03590. 
What happens before and after the artefact is more significant than the artefact itself

In one of his books, Andrzej Stasiuk, with his signature attention to even the most minute details, analyses various objects that are collected in a refuse dump located next to a rural household. Among these objects, he finds "idle horse treadmills with German inscriptions that resemble epitaphs, gears and sprockets without a hint of grease, cracked bridles without any trace of a horse's saliva, scythes eaten throughout by moisture that emit not a droplet of sound, hoops without barrels to bind, and hubs of pre-war cart wheels that rotate nothingness" (2001: 26). In this description, Stasiuk uses a naturalising device, by means of which an existential lack of something, such as "grease", "a horse's saliva" or "a droplet of sound", is meant to bring the material objects closer to us. He suggests that an object has died, as do living things. The remains of objects that used to be 'alive' rest in a peculiar cemetery, where they are devoured by rust, melted away by acid rain and overgrown with weeds. The fate of these objects is the same as the fate of the beings that brought them to life: they might not turn into nothingness; but they certainly turn into dust. However, is the state of being turned to dust, which is understood here as the disappearance of an object's essence, function or form, and its dissolution into the mineral or organic environment, not tantamount to nothingness? The purpose of this essay is to show that some of the material witnesses of passing culture do not die, contrary to the imagination of the writer, but they happen to emerge in their new function, much like a phoenix rises from the ashes. However, to demonstrate this it is necessary to go beyond pure literary imagination and rely on meticulous ethnographic research, which is the basic reference for the analysis conducted.

Similarly, also to pure philosophical speculation happens not to notice "the life after life of things", which phenomenon turns to be indispensable to maintain the cultural identity of subsequent generations of their users. The philosopher Stefan Symotiuk shares Stasiuk's view. In his description of the ontology of a refuse dump, Symotiuk notes that the dump "stands on the borderline of nothingness, which is the ultimate externality" (1997: 81). But before an object enters that state of nothingness, it usually progresses through the stages "of the preservation (expression) of discarded things. The object takes part in a broad range of situations: from being a precursor of refuse, through being a lone piece of refuse, to the beginning and end of its senseless existence in a dump" (Symotiuk 1997: 81). Let us invoke an example given by Symotiuk:

As long as a newspaper is lying on a bench in a park, it is not yet refuse. It wants something from us, and means something to us. But when the wind begins to pull it across the grass and forces it onto the street, dragging it like Achilles dragged the lifeless body of Hector behind his chariot, we feel that that the newspaper "no longer cares" and that it is simply fulfilling the fate that was encoded in its very existence. Initially, we perceive that the newspaper wants to adapt to 
the moment, and thus to bring us the news that is as close as possible to the "now" of the world. However, after that "now" has passed, the newspaper becomes unnecessary.

Symotiuk ends with a rhetorical question: "What other fate should it meet?" (1997: 84). As we can see, even a philosopher cannot resist the temptation to imbue objects with natural qualities, human qualities ("the newspaper "no longer cares") or even superhuman qualities ("the lifeless body of Hector"). Also, Symotiuk is unable to accept the fact that all things pass. Annihilation seems to be something much more consequential than simply the destruction of the material form of an object. Furthermore, in addition to the dissolution of the newspaper and the irreversible loss of information that it used to provide, we should consider the loss of the various content that can be disseminated by the language of the senses and the language of memory, and that is embedded in all things. For when an object is annihilated, so is its immaterial content, which is, perhaps, its most important type of content.

Is this inevitable? Do all things have to face annihilation? And when they do, must they also take with them the different meanings that define their user, the human being? Various examples from the history of culture show us that the answer is "no". Archaeologists are able to scour the depths of both land and water for artefacts, or fragments thereof. Sometimes these have even belonged to premodern cultures that lived close to nature and used its resources to fashion basic tools and decorations, such as wooden hoes, clay pots and jewellery made from bones or shells - not to mention the ruins of massive buildings, graveyards or roads that can be found in the area of the former Sumer, or in the sands of Egypt and the jungles of Yucatán. In fact, researchers of prehistory owe many of their discoveries to the existence of ancient refuse dumps, which constitute stand-alone repositories and witnesses to bygone eras and places, and have ultimately become peculiar treasure troves of these other worlds. The exploration of these contemporary traces forms part of what is referred to as garbage archaeology, and its aim is to investigate the human condition.

The expression treasure trove is not an exaggeration. Many museums have treasure rooms of various sizes, in which they store and display especially valuable artefacts, and some exhibitions are given the name "treasure trove" to underline the uniqueness of the exhibits. However, the road from the refuse dump to the museum is sometimes long and difficult, and is marked with the road signs created by collective axiologies, individual passions, the structure of the museum industry and even meandering political beliefs. Nonetheless, as Michael Thompson (1979) explains, if a piece of rubbish with no apparent value survives, it may nonetheless become a durable model for all the objects that are below it in the hierarchy of entities. This marks the beginning of a collection, which immortalises even those pieces of rubbish that were nearly annihilated, not to mention the objects that sometimes enter museum warehouses and exhibition rooms while still in the form of utilities, also called transients. Indeed, wrenching potential treasures 
from the hands of oblivion is a task that is undertaken not only by museum workers and professionals, such as archaeologists, ethnologists, historians or historians of art, but also by all persons who rescue material objects that embody a higher spiritual value for posterity, including national or even trans-national treasures. Family mementos, and even personal mementos that remind their owners of an important experience, can also become treasures from the viewpoint of the genealogy of a family or a local community (a village, town or region).

It should be noted that both the writer and the philosopher used the metaphor of "nothingness". Metaphysical intuition is the power (and privilege) of artists, thinkers and, possibly, "ordinary people" who are unfamiliar with the rigours of the scientific theories and methodologies that the aforementioned historians, archaeologists and ethnologists (in addition to museum workers) are obliged to follow. For instance, if the historian Pierre Nora (1989) were to use the term nothingness, he would likely want to miss the term's importance (specific to him and his discipline) for the purpose of understanding the past as a constituent of the present. Instead, Nora applies the well-established term history; albeit he gives it a meaning that is close to the aforementioned literary or philosophical nothingness that annihilates all things: "What we call memory today is therefore not memory but already history. What we take to be flare-ups of memory are in fact its final consumption in the flames of history" (Nora 1989: 13). It is memory - as the "living" substrate of human existence and the opposite of history - that becomes annihilated. Three aspects of this statement are notable here: the destructive role of history; its opposition to memory; and (as we may conclude based on the structural rule of its homologies and correlations) the creative role of memory. At the same time, the fatalism of the logic of history manifests itself here: the destructive force of history ultimately overtakes the creative power of memory. To quote a longer fragment of Nora’s work:

Memory is a perpetually actual phenomenon, a bond tying us to the eternal present; history is a representation of the past. Memory, insofar as it is affective and magical, only accommodates those facts that suit it; it nourishes recollections that may be out of focus or telescopic, global or detached, particular or symbolic - responsive to each avenue of conveyance or phenomenal screen, to every censorship or projection. History, because it is an intellectual and secular production, calls for analysis and criticism. Memory installs remembrance within the sacred; history, always prosaic, releases it again. Memory is blind to all but the group it binds - which is to say, as Maurice Halbwachs has said, that there are as many memories as there are groups, that memory is by nature multiple and yet specific; collective, plural, and yet individual. History, on the other hand, belongs to everyone and to no one, whence its claim to universal authority. Memory takes root in the concrete, in spaces, gestures, images, and objects; history binds itself strictly to temporal continuities, to progressions and to relations between things. Memory is absolute (Nora 1989: 8-9).

It is history that conquers and eradicates memory (Nora 1989), which on the one hand, is an absolute entity from the viewpoint of its non-alternativeness and hegemony; and on the other, provides a uniform interpretation of tradition 
and axiology, and knowledge about the origins and the goal of a community and its members. Historical science, which by its nature incorporates speculative thinking (primarily with respect to "grand" national events), undermines the otherwise unquestionable "minor", a priori narrations of memory. The divide between history and memory becomes greatest once history itself is subjected to scientific scrutiny: in other words, once the history of historiography emerges. Nora, in his discussion about this anthropological perspective, uses what may be considered as a canonical illustration: "Consider, for example, the irrevocable break marked by the disappearance of peasant culture, that quintessential repository of collective memory". In this repository, "We find an integrated, dictatorial memory - self-conscious, commanding, all-powerful, spontaneously actualizing, a memory without a past that ceaselessly reinvents tradition, linking the history of its ancestors to the undifferentiated time of heroes, origins and myth" (Nora 1989: 7). Those who are not anthropologists refer to this peasant (tribal) culture (as opposed to history, which is something that is practised in cities and academic centres) and the model-based authority of memory as a representation of the past, eternity, archaism, unchangeability and permanence. Consequently, the disappearance of the peasant culture inexorably threatens the refuse dump (in both its literal and metaphorical meaning) with nothingness. Nora seems to prophesy that the time of memory's existence will end along with this primal world.

Are we entitled to proclaim that only societies without memory exist in today's world; as opposed to tribal societies, which (according to Claude Lévi-Strauss) had memory but no history? Should we also conclude that a considerable change has occurred in the way societies experience the passage of time? Nora is less pessimistic: "Memory has been torn - but torn in such a way as to pose the problem of the embodiment of memory in certain sites where a sense of historical continuity persists" (Nora 1989: 7). These sites, or so-called lieux de memoire, including those that are historically important to France, "send us at once [...] to the archives as well as to the tricolor; to the libraries, dictionaries, and museums as well as to commemorations, celebrations, the Pantheon, and the Arc de Triomphe" (Nora 1989: 12). The list may be expanded with examples from Poland: the site of the Battle of Grunwald, the Czartoryski Museum, the Tomb of the Unknown Soldier, the National Ossoliński Institute, the Balthasar Behem Codex or the Jasna Góra Monastery. Due to their highly symbolic function, which nearly overshadows pure eventualisation, these objects of memory are subjects of interest for anthropologists who are searching for the meanings that make up the identities of individuals and groups, and the relationships between them and between people and the natural environment or even the extrasensory world. Let us quote Stanley Tambiah, whose investigation into the American culture of the late $20^{\text {th }}$ Century led him to conclude that "National monuments like the Lincoln or Jefferson memorials, or graveyard like the Arlington Cemetery, or battlefields like Gettysburg, are believed to enshrine a people's history or radiate their national glories - in all 
these instances, we have manifestations of 'participation' among people, places, nature and objects" (Tambiah 1990: 108).

As we have seen, Nora considers memory as part of the religious dimension, which is consistent with Tambiah's suggestion that all lieux de memoire should be classified as such. The historically and epistemologically significant relationship (pointed out in the title of Nora's work) between the two modes of experiencing time - that is, memory and history - is accompanied by the permanent emergence of auto-description and auto-reflexion, or "a sense of historical continuity", which has replaced the (admittedly non-reflexive, mythologising, all-encompassing, but at the same time unquestionable) understanding and practices of the eternal "now" that is memory. "Of course, we still cannot do without the word", to quote Nora once again,

but we should be aware of the difference between real memory, which has taken refuge in gestures and habits, in skills passed down by unspoken traditions, in the body's inherent self-knowledge, and memory transformed by its passage through memory, which is nearly the opposite: voluntary and deliberate, experienced as a duty, no longer spontaneous (Nora 1989: 13).

This new memory seems to be detached, weak and coincidental, as well as being primarily archival and material in character and depending on external media and visible signs (Nora 1989).

Can this historiosophical perspective be useful for an analysis of the titular rustic aesthetics that can be found in Spisz? We should begin by presenting an overview of these aesthetics. However, the question first arises whether - as the title of this paper would suggest - we are not dealing here with a hidden tautology. The readers may remember that Spisz, at least in its Polish part (which is the subject of this article), is a typically rural area that has never included any municipal congregation. Thus, mentioning rusticity with respect to a rural area should raise the suspicion that the research problem may have been formulated artificially from the very beginning, due to its apparent tautology. After all Spisz, as a rural region, is by nature rustic, which according to Oxford Living Dictionaries, means 'relating to the countryside; rural' (Oxford Living Dictionaries). It is worth mentioning at this point that the rudiments of general methodology state that the correct formulation of a research problem is a necessary (though not sufficient) criterion for solving it. Perhaps then, the problem is being wrongly formulated or, more specifically, it simply does not exist at all?

While these doubts seem justified, they require a closer analysis that should take into account the significant amount of mythologisation that selectively borrows and filters certain aspect of the image of Spisz (and in fact, most rural areas) and the figurativeness in our notion of the countryside and rusticity. These were addressed in Robotycki's and Węglarz's (1983) insightful work. Indeed, a somewhat mythologised image of rural reality can be found not only in the popular imagination, but is frequently also found in scientific studies. This image involves 
the simplicity of life, permanency of the places of residence, working in the field, religious devotion, high moral standards, attachment to tradition, the power of authority, conservatism, social control and handicrafts. Robotycki and Węglarz suggest that this image has been solidified thanks to such luminaries of $20^{\text {th }}$ Century Polish science as Stanisław Pigoń, Józef Chałasiński, Kazimierz Dobrowolski and Józef Grabowski. Also, the image itself, which is enriched with an idyllic aura of "peaceful countryside, joyous countryside" (a quote from the Polish $16^{\text {th }}$ Century poet Jan Kochanowski; although of course, apart from being peaceful and joyous, the countryside has its share of problems), seems to be highly immutable. Even though the rigorous eyes of the modern ethnologists, sociologists, economists and demographers are able to penetrate this mythological layer of preconceptions, the image remains deeply rooted in popular awareness. The following statements from a tourist visiting Spisz in 2013 illustrate this fact well: "In all the villages yesterday, there were a lot of beautifully dressed highlanders driving wagons"; "People can provide food for themselves every day, and they make their own milk. The cows are already mooing in the evening, demanding to be milked, because their udders are so full"; "There is no rushing around for cash in the countryside. (...) It's as if time has stopped (...) and the children are running around playing"; "Yesterday, I saw a guy driving an old Ursus tractor. He was singing beautifully, singing highlander songs".

These statements are so strikingly hyperbolic that they cannot avoid attracting the attention of even someone who does not deal with deconstruction on an everyday basis. However, the public domain is rarely filled with narratives that have such saliently mythologising intents. Usually, the narrations are much more restrained; although they are still not immune from scrutiny. Such narrations most often appear in the media, and while they underline the ongoing modernisation of the countryside, or even its deagrarianisation and transformation to a livestock economy, still strongly promote the sense of a different world that lies far away from urban aggregations and the urban lifestyle. The countryside is also portrayed in the media as the site of festivals, where folk bands display their skills, and a place where tourists from the city can find cheap accommodation during the summer and where religious ceremonies are held in the best fashion possible. This image is complemented with a sense of ecology, and of rural people living in accordance with the cycles of nature. At the same time, the image seems to confirm the presence and persistence in the countryside of Nora's 'real memory', which is embodied in the aforementioned qualities of the rural reality, in contrast to the urban reality which has irrevocably been doomed to have history but not memory. If we accept the presence of such a mythologised framework (or cliché) that promotes an orderly, ideological image of the countryside, then this leads us to ask whether the combination of rusticity and the countryside was a form of tautology after all, and consequently, whether the research problem was not wrongly formulated. 
Indeed, there is no tautology, neither salient nor hidden in the research question. The countryside has ceased to be rustic, folk or rural as described in the subject literature from the $19^{\text {th }}$ or even the $20^{\text {th }}$ Century, especially the countryside in Podhale and Spisz. The $21^{\text {st }}$ Century has arrived, and any keen observer is bound to notice the deagrarianisation and modernisation of the countryside, as well as the widespread influence of the urban lifestyle and a strong presence of the media (including the Internet), the increase of popular culture and typically suburban architecture and aesthetics, changing customs, the development of services (primarily touristic services), intensified permanent and temporary labour migration and, last but not least, improved education. These processes have been notably accompanied by a strong regionalistic movement, which has given rise to many regional folk bands in the last 25 years, specifically during the aforementioned period of modernisation (at least one such band is active in Spisz). It is also notable that the movement has focused on spectacularity, theatricality, dramatisation, reconstruction and revitalisation with a considerable dose of aestheticisation. Its main mission - as Nora would put it (Nora 1989) - is a faithful reconstruction, which is a characteristic of modern memory that in turn is now limited to archivememory. The aforementioned outdoor events, such as Spiskie Zwyki during the carnival or Spiska Watra at the beginning of summer in Spisz, constitute Nora's lieux de memoire. They are places of memory that also have their particular temps de memoire: that is, a separate time during which the locals celebrate their cultural past. However, these events seem to be reduced to theatres of memory, and are in fact only historical memory. These theatricalised forms of experiencing the local culture and heritage exemplify a spectacle-based practice that involves cultural pedagogy but, at the same time, is fleeting in its periodicity, particularly as the Municipal Office of Culture is obliged to organise them annually as part of its event schedule. Nonetheless, the events act as vehicles of memory, even though they resemble a visit to a museum or an archive, and in this case, the archives of the history of the local culture belong solely to the framework of historical memory. This real memory (in Nora's understanding) seems to already be a song of the past, which is being experienced by the contemporary residents of Spisz.

The intensity of this change has possibly never been higher in the history of not only Spisz, but of all rural areas in Poland. The change is particularly obvious with respect to the country's material culture, which always heralds new things to come. The wooden houses with the architecture, stylistics and building techniques that dated back to the beginnings of human settlement in these regions, hundreds of years ago, are now gone. They have been replaced with mostly uniform brick houses that were designed by external developers. Likewise, the traditional furniture and implements, which were frequently the work of a local carpenter, stove fitter or potter, are now things of the past that have been replaced with anonymous mass manufactured household equipment. Handiwork, which used to be represented by home cooking, field work, animal herding, woodworking, tailoring or 
wickerwork, has also been taken over by mechanisation. Moreover, this mechanisation concerns only a few of the aforementioned forms of artistic and occupational activities; while the other forms have simply ceased to exist. This radical change also encompasses all forms of material, vocal and musical folk art, which have been modernised and altered into the cultural capital of (primarily) the local educated elites, or in the worst case, into the memories of the older generation. In Spisz, only the local dialect is a cultural element that has been in use continuously for generations, and even then not all residents of Spisz can speak it, and those who can frequently do so only at home. It is true that a visitor to Spisz may have the justified sense of being in a rural area. After all, apartment blocks, multi-lane roads and giant shopping malls are mostly absent here, and the villages are separated by fields, meadows, forests and more and more frequently, fallow land. On the other hand, a grazing cow is a rare sight, and the occasional flocks of sheep on the nearby slopes are often the only remainder of the old economy. However, the visitor would first and foremost be struck by the similarity to the aforementioned suburbs, with their low-rise infrastructures, carefully mown lawns, pavements and brightly-lit streets that have been named in the modern manner, rather than after the traditional hamlets.

On the other hand, although the rural landscape bears signs of modernisation, especially in its visual and material aspects, it is not fully uniform. In addition to its varied architectural forms and household aesthetics, this lack of uniformity concerns the brand new public infrastructure, including the new streets, pavements, pedestrian crossings and streetlights. All of this modern infrastructure is interspaced with typologically alien elements that even a historically-untrained eye will recognise as belonging to the past, such as: carriages standing on lawns, restored and adorned with flowers; or carriage wheels hung on the walls of houses, to which the locals will sometimes attach lightbulbs to create lamps for their entranceways. The alien elements also include old wooden troughs that today serve as large flower pots, or long discarded tools: wooden harrows that hang on the walls of a barn (which in turn serves as a garage), sometimes in the company of horse collars, rakes and baskets; spinning wheels that rest in porches that have been built particularly for this purpose; or rings from chaff cutters that are used as parts of benches in the yards (another case, like the carriage wheels, of a functional adaptation of a no longer useful device). Lastly, the alien elements may simply be composed of furniture that is displayed outside the house, such as old dressers or wooden benches, which at least retain some of their original functions.

We should end this selective list with the obvious comment that this unevenness of the cultural landscape is not unique to Spisz, as similar forms can be found throughout Poland (for more on this subject, see Tomasz Siemiński's (2010) monograph about such elements in the visual composition of the countryside in Kaszuby). If we were to echo Stasiuk's literally vision, we would probably conclude that the carriage displayed outside a local resident's house contains not a trace of 
hay, nor are there any patches of grease on its wheels or lumps of soil on the harrow; likewise, there is no animal sweat on the horse-collar, no reflection of a cow's mouth is seen on the water in the trough, and the spinning wheel can now spin only nothingness. Even the wooden bench, a piece of furniture that has retained nearly its entire functionality, no longer provides rest for a peasant family who are weary after a day spent working in the field; but instead, provides this function to visitors from the city who were attracted to the area by new forms of rural enterprise, such as agritourism. However, the analogy with Stasiuk's literary intuition is an oversimplification. Stasiuk's peculiar metaphysical approach concerned discarded objects, or refuse that had lived out its days in a wild or domesticated orbis exterior. In contrast, the objects that are provided as the examples above are not refuse, even though many of them may have been through such a period before they were recovered from barns, dark attics or even personal junkyards. These objects are what Thompson describes with the term durables. They function as models, although modelling refers here to things that are already gone, and things that constitute traces and mementos of the past. Using the word memento with respect to such specific objects of various sizes proves to be a key for understanding the role of all objets de memoire (such as those that can be observed in the Polish countryside), in that they play the role of remembering, reminiscing, immortalising and commemorating that which has passed. However, these terms refer not to Nora's 'real memory', which is self-unaware and is thus obvious and permanent; but to the historical memory, or 'archive-memory', which is self-aware, nonobvious and impermanent. It should also be noted that the meaning of the word memento encompasses a degree of intentionality - of deliberately reaching out to something, focusing attention on it and ascribing a value, content and definition to it (a process which, due to the sheer number of different individuals and groups that engage in it, yields different results for the same objects).

This history-memory understood in the above manner constitutes a repository of both material and immaterial mementos, and according to Nora, these are the remit of historians, museum workers and other specialists in the passage of time. Even so, the objets de memoire from Spisz can remind one of museum pieces that, albeit in a slightly different, methodical and conceptually-ordered manner, are displayed in buildings constructed specifically for this purpose, such as the British Museum in London, the Louvre in Paris or, in particular, the Ethnographic Museum in Kraków. The objects collected in these institutions, which are similar to those found in Spisz but with older and more unique forms, are appropriately ordered, well-cared for, exhibited, preserved and described. In contrast, the objects from Spisz and the other objects that are displayed in rural households in many other areas have not undergone these processes. Nevertheless, given the fact that they are displayed, we may assume that they are revered in a fashion, and the fact that someone has taken the effort to preserve, recover and repair them brings to mind associations with museum exhibits. Let us provide several responses from 


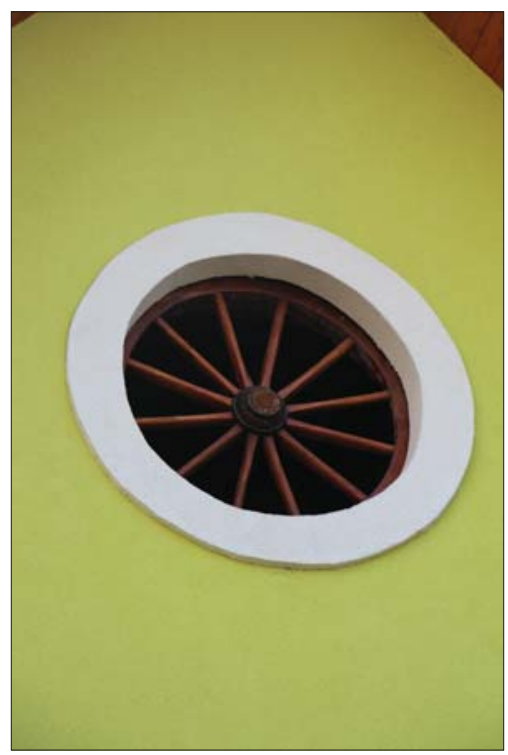

Figure 1.

Author: Janusz Barański

by the amateur curators and caretakers of memory from Spisz (who are quite numerous), and examples of the actions undertaken by them. The embodiments of these memories are objects that at some point were considered to be unnecessary, outdated, embarrassing or simply trash.

Example 1 (see Figure 1). A brick house is built on the site of an old wooden one, which contains peculiar traces of past times in the form of wheels from a wooden carriage that the owner inherited from his parents. The wheels are mounted into the top part of the walls, at the level of the attic. Thus, the wheels resemble the rosette windows found in Gothic religious architecture, even though the entire tracery is composed of wooden spokes - once an integral part of the cart, but now serving as a decoration. "These wheels are part of my patrimony", is the owner's explanation of his decision to use this unique architectural ornamentation. The top part of the house used to be panelled, which was a deliberate reference to traditional wooden architecture. At that time, the rosette wheels would have harmonised better with the aesthetics of the house. Unfortunately, to the owner's regret, his adult son insulated the walls with a polystyrene material hoping, of course, to save money on heating.

While the wheels are currently the house's only visible connection with the past, there is an in-house workshop that contains many more objects that the owner inherited from his grandfather through his father: hatchets, saws, planes, vices and a lever for lifting beams. "I like something different, something old, something that has survived", the owner admitted. "I like old things. I like that people used them in the past, and that they did well with them, you see? Some 


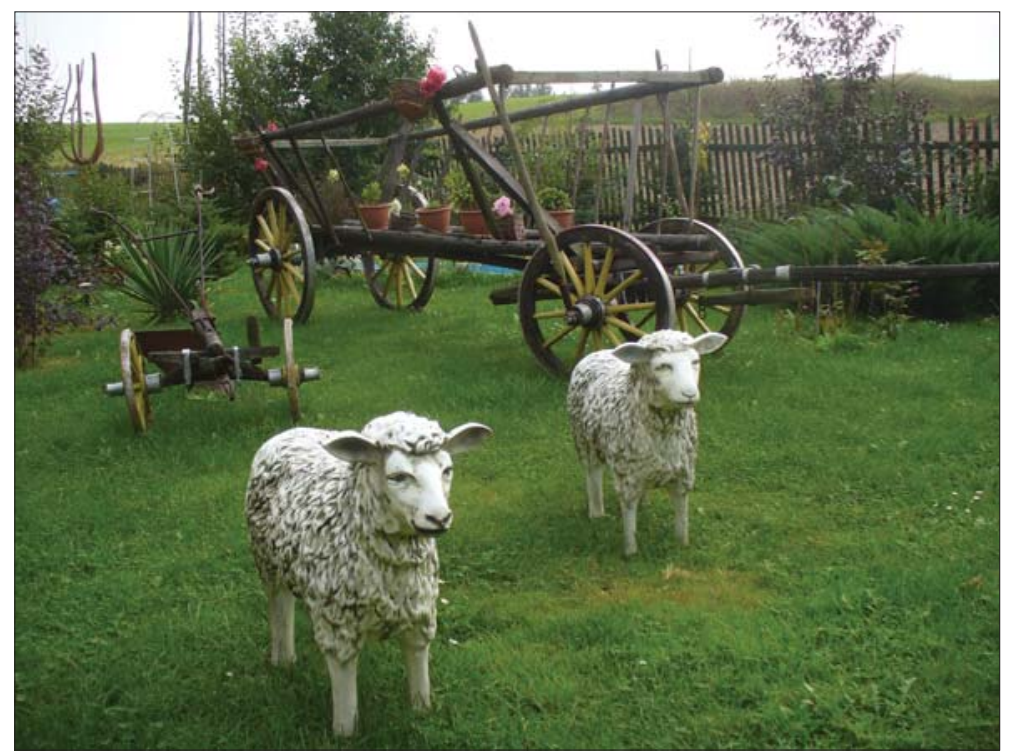

Figure 2.

Author: Janusz Barański

of these things were primitive, but practical. Our grandparents would think for themselves, and they managed to get by, you see?" The owner also underlines how important these remnants of his family heirlooms are: "This is all my inheritance. This is what my parents have left me. They left me something to remember them by. I've also got some things from my grandfather and grandmother in the house. It's all very interesting, you know?" The owner also complained about the popular attitude towards local heritage. "People like to destroy and burn everything now, because they do not need it anymore". And as a result: "All of this is disappearing." Instead, this man believes that the local population should focus on preserving the remaining objects of the past: "These old things are mementos. We need to have something, because it's all disappearing"; "My grandchildren might want to have something to remember me by. (...) Maybe I'll give it all away. Maybe they won't sell it or throw it away. If only this much remains, I'll be fine with it"; "We still have something from the past, right?"

Example 2 (see Figure 2). In front of a wooden (though newly-built) house stands a horse carriage, which the owner received from her relative, who wanted to burn it. The carriage is in heavy disrepair, and many parts are missing. In the spring and summer, the owner decorates the carriage with flowers and works to repair and preserve it. Next to the carriage is a wooden-wheeled plough and two plastic rams. "Looking at this carriage brings back memories of my uncle. I remember him driving it to get hay. I remember him using this carriage for his work", said the owner of the objets de memoire. She went on to comment about the plough: "A lot of young people, when their parents die, either sell their old house 


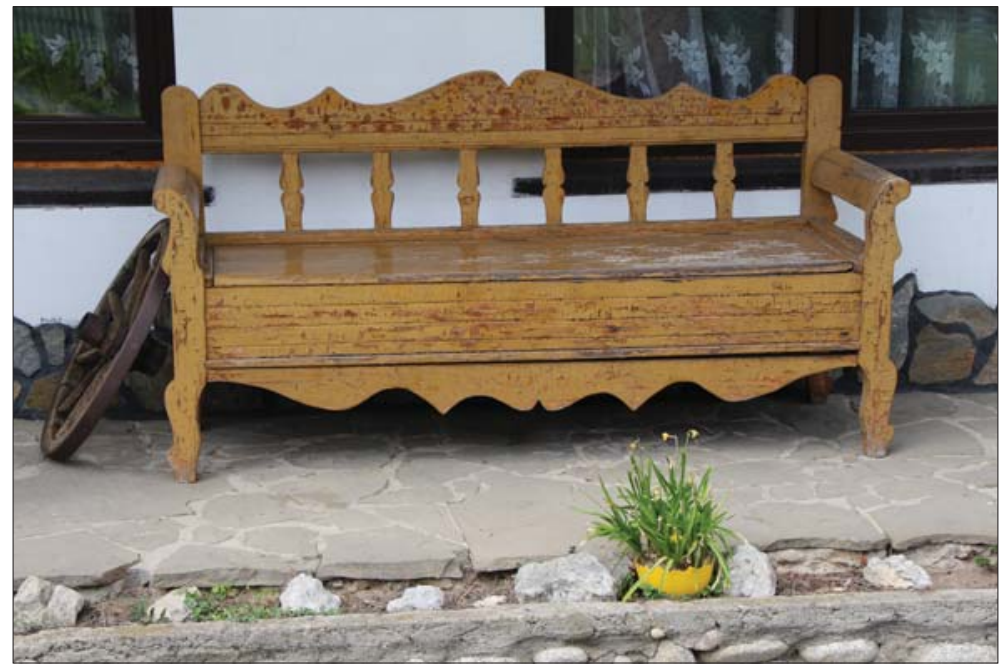

Figure 3.

Author: Janusz Barański

or renovate it. I think that most young people do not think, even from time to time, about their descendants, about the future, or about the people who will one day forget what a wooden plough looked like." She added with a hint of nostalgia and cultural pedagogy:

For me, it's nice to have this carriage in my garden. It's nice to put a flower pot on it. Whenever I approach it, it always brings me memories. Besides that, whenever tourists take a walk along the road, they say, "Oh, that's a very interesting carriage you have there, madam." This somehow shows other people [what things looked like in the past]. For instance, outsiders who walk by my yard often say, "So they used to transport hay on carriages like this one, didn't they?" (...) I've heard a few comments like that.

This cultural pedagogy is meant for the younger residents of the area: "It's for all the young people who live in Spisz. They should know what people in the area used to plough the fields in the past, what they used to harvest and mill the wheat, how they cut the straw, made flax, and ground grits. These things were a staple way of life not that long ago, and now they are being replaced." In this context, the aim of exhibiting old objects such as the carriage or the plough is to illustrate "the direction we going in now. [It's meant to make people think about] whether the changes we make are for the better, and whether what we had before or what we have now is better. Maybe even comparing such things (...) can help predict what is and what may come next." The local populace displays two different attitudes a personal and a social one - with respect to such objects from the past, which is evident in the following statements: "I'm sentimental about old things. They help me remember the owner himself, who was important in the family"; "That's not to say that I wouldn't find other things from the region to be important, if someone 
were to gift them to me. They would be important for me, because I was born and raised here. I want to promote this culture, so that people don't forget about it so fast, because people forget more and more things as the years pass".

Example 3 (see Figure 3). A brick house has a roof covered with wooden shingles. The house is also partially surrounded by a woven hazelnut fence which, the owner explains, is going to replace the old metal mesh fence. On the porch stands a large wooden bench, made by the grandfather of the owner's wife. Next to this bench is a spinning wheel. The owner's wife reminisces nostalgically about the times when the bench was one of the few pieces of furniture in the house, which in fact, were all made by her grandfather: "We would always sit on that bench. (...) For instance, you could take a nap on it after dinner." The bench is still used today, often by visitors who rent rooms in the house: "Sitting on the bench is a good opportunity to talk about one's ancestors, about coming back to where you used to live, you know. (...) This is how people come back to their places of origin." The bench could easily become part of a collection in many museums, but this is impossible: "I'd never sell it. I don't think of these things in terms of money."

A lamp hangs from the roof of the porch, made from an old carriage wheel, with the light bulb attached to its centre. Also, on the walls of the garage in the cellar hangs a sokha, a horse-collar, a scythe and many traditional carpentry tools. In the part of the roof on the other side of the house is a wooden beam with a carving in the shape of a rosette and the date 1895. The owner, who is a construction worker, "rescued" this beam from a building that was about to be demolished. Finally, at the back of the house is a wooden shed, which the owner built himself: "I'm going to make a house someday and I will move all these old things there. Everything's ready to be moved. Because people don't know what all this is", the owner explained authoritatively. He added with irritation, "Young people don't understand anything." This statement, which the owner delivered using the local dialect with no hesitation, followed a more broad, visibly passionate one:

Old things! When we take apart an old house, the guys know that it's wise to hold on to some things. You never destroy them, because you have $f^{* * *}$ ing respect. People used to work with these things, they made a living with them, and they still had more time. God Almighty, I feel like I need to talk about this. Did we have washing machines? No, we didn't. So we washed our clothes in the stream. And you had to watch your trousers or they could get carried away by the current. And the women were healthy! The beets had to be cooked and the cows had to be milked, and the women still had time. Unlike today, when a woman doesn't have the time to paint her nails because she's spent too much $\mathrm{f}^{\star * *}$ ing time in front of the mirror. What's happened to culture nowadays?

Example 4 (see Figure 4). A two-storey brick house is covered with siding that is built in a style reminiscent of the suburbs rather than the countryside, with a mown lawn, cobbled driveway and a metal fence. The only old element that is visible to passers-by, as in one of the previous examples, is a wooden carriage which stands in the front of the house, in the very centre of the lawn. This owner 


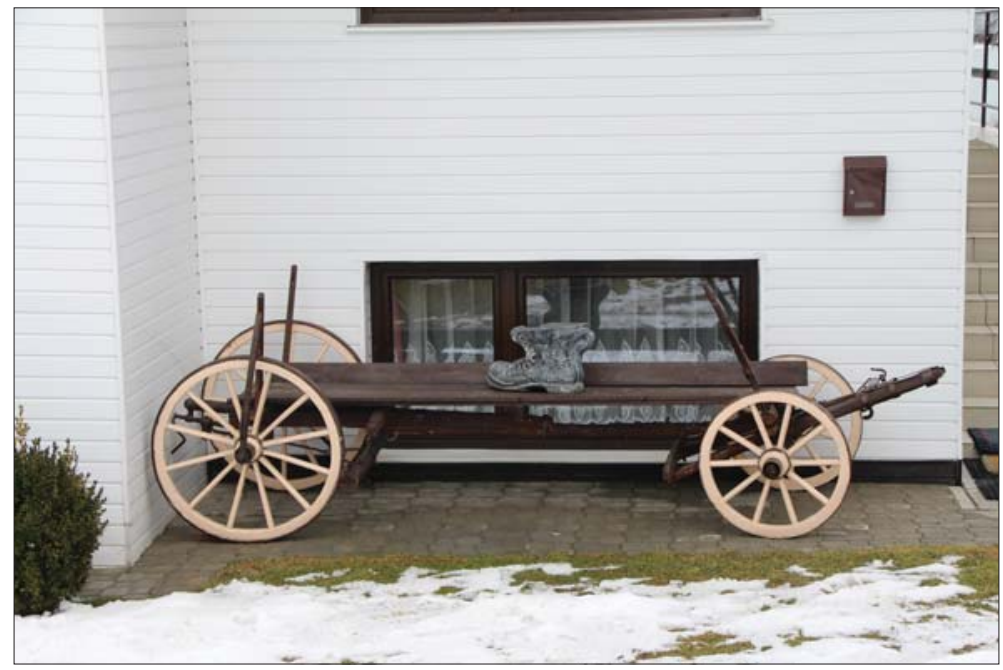

Figure 4.

Author: Janusz Barański

also inherited the carriage from her ancestors. She said, "I used to ride on this carriage with my grandfather when we went to work in the field. (...) This is my inheritance from him." She openly admits that the carriage has a sentimental value for her: "I'd never sell it. That would be like selling my own grandfather, or as if it was someone else who used to ride that black horse and some other children who used to ride on the sheaves". Her daughter, who is well-educated and lives in the city, added something about the current function of the carriage: "It has some historical value, and it's worth having something like it here. (...) It's like the memory of our ancestors, or like a historical memory." The owner continued, "In the summer, we grow a lot of geraniums on it, so we don't need a garden since the carriage is enough." This partially explains the lack of a garden beside the house, which is an increasingly common occurrence in all rural areas.

Another remainder of the traditional local culture are the cobbled paths. While these are invisible to passers-by, they were made manually by the owner's mother (who has since passed away) using a mould. The mould was gifted to the Museum of the Castle Complex in Niedzica (when the mother was still alive). Additionally, the mother's folk costume was gifted to a local regional activist. All of this indicates that there is a certain limitation, in that only some (relatively durable) witnesses of history will survive, and makes the lack of a greater whole (which is represented by only a few remnants) even more saddening. It also helps to establish the owner's identity: "I feel like a Spiszan, and I take satisfaction in being born in Spisz." This statement, while laconic, originates from a deep experience of the genius loci. The owner confirms this through her poignant admission that "Anytime the highlanders play a song, I start crying immediately. Anytime people from 


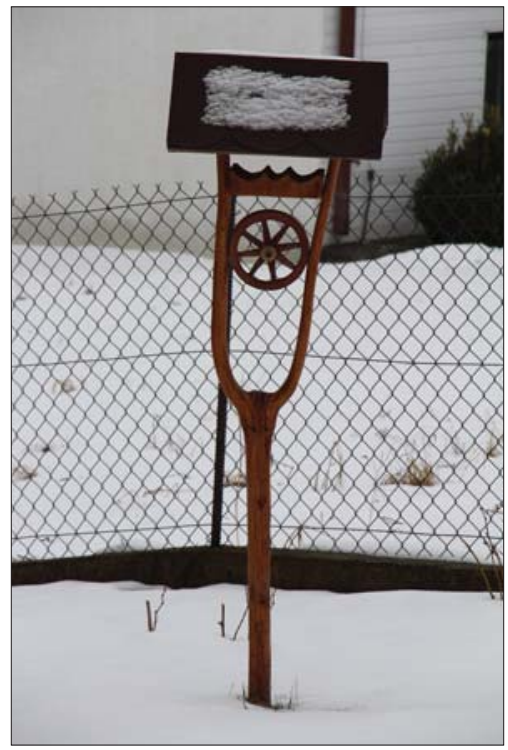

Figure 5.

Author: Janusz Barański

Spisz play, I cry. (...) When I return from Spiska Watra, I'm so moved that I feel as if I've been to a funeral.' The fact that the owner uses the local dialect in her last statement, even though she used Polish literary forms in her previous responses, seemed to fit her accompanying emotions.

Example 5 (see Figure 5). Once again, a brick house is located in a similar vicinity with a small shed, small garden and a metal fence. To the owner's regret, the small size of the plot leaves no room for any other building, including a chicken coop which would provide healthy eggs; although there is a rabbit cage on the plot. The owner also nostalgically remembers the time when he was young, and nearly all the households had a horse, cows, sheep, fowl and rabbits. Each house was wooden, and was healthy and pleasant to live in. "If I won the lottery, I'd demolish this house and build a wooden one for my family; a real one, with wooden drainpipes", said the owner. As before, the wheels of a carriage that the owner inherited after his parents constitute this household's reminders of the past. "They always remind me of my parents." Unfortunately, the owner was only able to rescue the wheels. He cleaned them, repaired them and coated them with a transparent varnish. One of the wheels hangs from the roof of the gazebo and serves the popular (as we have seen) structural function of a lamp. Two other wheels are attached to a wall of the wooden shed, where they are displayed along with several flower pots and decorative polypore fungi. The fourth wheel is covered with a small roof and has been placed between the varnished, barked, bifurcating branches of a tree trunk that is buried in the ground. It serves as a totem to maintain the continuity 


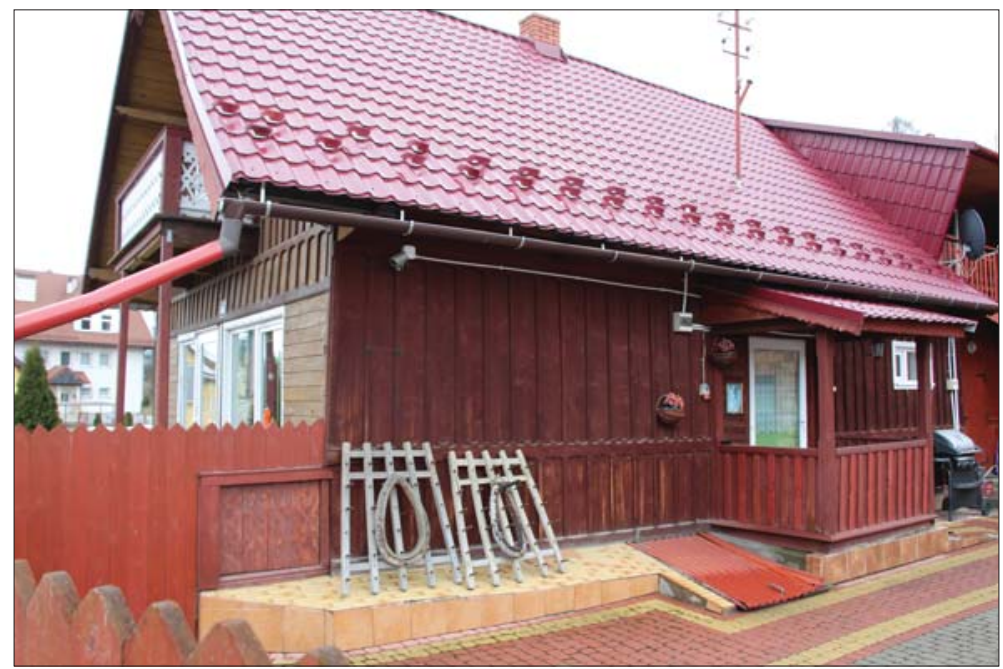

Figure 6.

Author: Janusz Barański

of the local heritage: "Tradition says that a house should have a wheel like this because people used to ride in these carriages, so let's allow this custom to stay", said the owner. He then made the more general statement that "This is important because it's from here. Not because I got it from my parents, but because it's from here." This remainder of the past is a part of the broader perspective: "For me, this is where my roots are. For me, customs are something that should never disappear, because we've kept them for generations. (...) Our dialect, and all these traditions, should never be rooted out. (...) When I hear the highlanders sing at our festivals, I cannot eat for two or three days and instead must keep listening, because this is everything for me. Because this is where my roots are."

Example 6 (see Figure 6). An old wooden house, and is covered with metal roofing tiles, while the lawn is paved with concrete cobbles. Propped against the wall, on the elevated part of the concrete path (which is the most prominent spot on the lawn), there are two wooden harrows from which hang two horse-collars. The owner revealed that these are mementos from her parents, who were farmers several decades ago, as was nearly everyone in the area. She explained, "We've kept these out of sentiment. They express our admiration for our ancestors and for the other people who knew how to use such tools. (...) I have great respect for the local people, because to live here you needed to be very tough (...) you needed to work really hard to eke out a living." However, these feelings were accompanied by a particular cultural mission, and the material remainders of the old times were only a part of that mission: "We have to do what we can so that our children continue to use our dialect. (...) Let them know where they come from. I think that this is very important. A bit of the dialect 
and a bit of the folklore has to be preserved, because if we're lazy our children will never know these things. They'll have no-one to learn from and all of this will die out someday." The mission involves promoting cultural education among the local population, as well as among outsiders who visit the region for holidays in the mountains: "I would like - my subconsciousness is telling me this - I would like to let these people understand that there is a region like our tiny Spisz and that it has its own culture. To let them understand that there's still something that makes us different from other regions."

The aforementioned material objects, which their owners display with reverence and engagement, have been taken over (in the broadest sense of the expression), preserved and inherited, and thus constitute a form of heritage. Barbara Kirshenblatt-Gimblett (2004: 1) wrote this about this type of representation of the past and metacultural phenomenon: "I define heritage as a mode of cultural production that has recourse to the past and produces something new. Heritage as a mode of cultural production adds value to the outmoded by making it into an exhibition of itself." This aspect of the exhibitive, almost museum-like, imagination, which is (after all) visualised by displaying historical objects, can also be found in the following response from the owner of the carriage and the wheeled plough: "I wish that all these things from the old times would not disappear so fast. I wish we could leave something for the young people." When asked what the point of that would be, she answered, "Memory, I think." In turn, the owner of the harrows and the horse-collars thought that the regional youth should undergo a cultural education: "They should know where they come from."

This and several other responses also underline, directly or indirectly, the importance of having a sentimental attitude towards the objects from one's own culture. This sentimentality motivates the locals to approach their inherited material and immaterial goods (which, as we have seen, have sometimes been preserved only fragmentarily) with a certain amount of reverence. "The traces of the past gain importance whenever there is a risk of losing them and whenever we have already lost them", as Krzysztof Kowalski (2013:100) stated. In the latter case, only the memory remains. Nora would likely conclude that the very fact that memory was explicitly indicated as the motivation for action (in this case, for the action of collecting and exhibiting the material witnesses of one's cultural past) is proof of the self-aware, self-reflective, archival and historical character of memory. "Real memory", or the implicit, unaware and non-reflective memory that is immersed in a cosmos of meaning, seems to be absent here or, at least, to not concern the rustic objects discussed in this article. This is because these objects already belong to the sphere of heritage, or the sphere of the "self-conscious selection of valued objects and practices" (Kowalski 2013: 100), in contrast to the sphere of habitus, which 'refers here to the taken for granted' (real memory).

On the subject of refuse, Symotiuk (1997: 86) wrote, "The common trait of throw-away objects is everything that ends with '-lessness' (listlessness, helpless- 
ness, defencelessness, homelessness or powerlessness, owner-lessness, etc.)." The aforementioned examples are objects that have been retrieved from the refuse dump, literally or metaphorically, and delivered from a material death. The wife of the owner of the wheel spokes-turned-tracery said this about her husband's involvement in rescuing old objects: "For instance, people gave us a lot of old things, you see? When people were about to destroy something or throw it away, he always took it from them." Once rescued, these object are no longer refuse on the verge of death, and instead become (as part of the not always self-aware intention of turning them into an exhibition) treasures in their own right, in a similar manner as the hallowed artefacts that lie in display cases and in museum warehouses. After being physically and conceptually removed from their original environment, the objects are transformed into artefacts with a new function. They are no longer listless, because they have the ability to act, as their owners seem to believe: "Whenever I approach [the carriage], it always brings me memories." Also, they are no longer helpless, because they can manifest their roots: "Some of these things were primitive, but practical. Our grandparents would think for themselves, and they managed to get by, you see?" They are also not homeless, because they settle in to their new environment: "[Young people] should know what people in the area used to plough the fields in the past, what they used to harvest and mill the wheat, how they cut the straw, made flax and ground grits". They are not owner-less, because they belonged to someone from a previous generation: "This is all my inheritance. This is what my parents have left me." In this way, the reclaimed carriages, ploughs, wheels, troughs, rakes, horse-collars and other objects become the opposite of refuse: they activate the imagination and memories, and acquire the ability to be agents through their effect on human beings and through their superiority over other "ordinary" contemporary objects. They defend themselves very effectively with their shining varnish or museum-like exhibitions, and powerfully represent the idea of a golden age in the past, embodying a given household and becoming masters over their owners.

The phrases "like a museum exhibition" and the "intention of turning them into an exhibition" come to mind naturally when one is analysing the phenomenon discussed in this article. In his study of cultural heritage in the southern US, Steven Hoelscher (2003: 661) uses the term displays of memory with respect to the signs of memory that are subject to particular care and exhibitions (pieces of art, photographs, monuments, folk festivals and even the landscape). With regard to this point, Hoelscher quotes Andreas Huyssen: "The past is not simply there in memory, but it must be articulated to become memory" (2003: 661) (emphasis in the original). Let us add the statement that this articulation concerns an exhibited memory, which in our case is embodied in objects, archives other things and is archival itself, and is both historical and self-aware, as is evidenced by the statements quoted above. Nora's real memory did not require any spectacular interventions regarding its material or immaterial content. Here, however, we 
are dealing with historical memory, and the "displays of memory" that represent it 'are not passive containers, but are active vehicles in producing, shaping and giving meaning to cultural memory and heritage. This is especially true when the past being recalled stretches beyond the lifetime and experiences of the individual, to encompass an imagined community such as a nation-state or region' (Hoelscher 2003: 660-661).

Researchers interested in material culture have also raised the notion of "the language of objects". However, this notion has nothing to do with verbalism and little to do with textualism, even though the latter still seems to constitute the model for the interpretation of all meanings. The issue here concerns, first and foremost, the fact that the messages that are "sent" by the objects do not take the form of arbitrary metaphors, but rather that of indexing metonymies which "speak" though their material, shape, colour and state of preservation. At the same time, these messages are embedded in their material surroundings, with different sequences of events and the (frequently ephemeral) memories of human beings. We interpret objects in terms of their aforementioned constituents, which form an indistinct code that in turn is a tool enabling all persons who undergo a particular set of enculturating processes to use it to a varying extent. Consequently, our interpretation has the characteristics of a Gestalt-esque perceptual field (Barański 2007: 196). The responses from the aficionados of the objets de memoire are like mirrors that reflect the subject of these responses. The reflections encompass verbal narrations, traces of memories, emotions and outbursts of nostalgia. This cognitive horizon is ultimately determined by the culture as a whole which, according to Paul Graves-Brown, "exists neither in our minds, nor does it exist independently in the world around us, but rather is an emergent property of the relationship between persons and things" (2000: 4). Graves-Brown's emphasis on things, which are the most durable means of cultural expression, is significant and goes beyond our popular convictions about things. Henry Glassie describes this type of conceptualisation in the following manner:

There are people, I know them, who think human beings think in words. Some may, sometimes I do, but usually I do not. Instead I think in images, quicker and more enormous than words, which I must struggle to reduce and transform into the conventions of speech and writing. Only some of the thinking of some kinds of people (the kinds who become linguists and historians and who write convincingly about all of us out of their variety of experience) fins itself expressed naturally in language (...). An artist's letters are fascinating, but they are small things by comparison to the artist's paintings. A building contract is a petty thing by comparison to a building, a prescriptive essay on domestic décor is as nothing next to the actual interior of a home (...). The artifact is as direct an expression, as true to the mind, as dear to the soul, as language, and, what is more, it bodies forth feelings, thoughts, and experiences elusive to the language (Glassie 1991: 254-255).

The rustic objects discussed in this paper also seem to forward that mission. As with traditional museum exhibits, they belong to the boundary between the past and the future. In other words, they constitute a conveyor belt that transports 
the past into the present, along with whatever are the most valuable aspects of an experience and with the opinions of those who have saved them for the future generations. These rustic objects embody a state of suspension between the "not anymore" (the previous function) and the "not yet" (the new function). They are objects that have avoided the fate of refuse, thus conquering their own death and emerging in their new function, much like a phoenix rises from the ashes.

It is worth noting at this point that the biography of an object is usually marked by a cyclic changeability in its functions, such as the functions indicated by $\mathrm{Mi}-$ chael Schiffer (1999): the technical, social and ideological functions. All of these functions are a part of the potential of every material object, including the aforementioned carriage displayed in front of a modern house in Spisz. Undoubtedly, the technical function of the carriage was dominant in the original cultural context from several decades ago: i.e., the carriage served as a means of transporting crops. During that period, and moreover several generations before, carriages sometimes also played a social function: they would indicate the owner's wealth, in contrast to poorer farmers who could only dream about having such a vehicle. But today, the carriage only serves an ideological function: it is a symbol of a bygone idyll when, according to those we interviewed, "People had time to sit down and talk with one another about their problems, and to simply support one another in some way." We may refer to Krzysztof Kowalski's notion of myth, which he developed as part of his musings on heritage, to define what underlies such an idyll, namely, "A particular logic or grammar of the mythical discourse that treats specific objects as words and organises them into greater wholes (sentences)" (2013: 103). In our case, such material myths are, without a doubt, the aforementioned objets de mémoire.

The empirical testimonial presented above, indicates that the artefacts (understood, after Nora, as historical memory rather than real memory), which represent the past and constitute material connectors to what has passed (in other words, they are the emblems of a bygone cultural state of affairs), are equally important for establishing the sense of local distinctiveness as heritage that is represented by the local dialects, customs and folklore. Some of the residents expressed this feeling of distinctiveness explicitly: "I feel like a Spiszan, and I take satisfaction in being born in Spisz"; "For me, this is where my roots are"; "I would like it - my subconsciousness is telling me this - I would like to let people understand that there is a region like our tiny Spisz and that it has its own culture." These responses develop into: pedagogical initiatives (regional educational routes created as part of the school curriculum and regional quizzes); reconstructive initiatives (the restoration of historical customs, such as stawianie moja, which involves erecting a festive pole, or chodzenie $z$ koniem, which features a cheerful parade during which a resident wears a horse costume); cultural initiatives (folk festivals and exhibitions of local art); and economic initiatives (for the promotion of the region). This proves the existence of a large amount of reflexivity and discursivity 
within the reflexion on one's heritage, against the background of on-going, unavoidable changes. In this way, Stasiuk's 'hubs of pre-war cart wheels' do not have to rotate nothingness; instead, as their owners describe them, they may become the embodied symbols of the "ancestors", "inheritance", "origins", "roots", "the region", "past", "memories" and "tradition". Finally, they may also become "mementos", which have been preserved out of sentiment and that guarantee the emergence of "historical memory" - a term that is consistent with Nora's proposal! Memory, in turn, is necessary for the establishment of one's identity, which in this particular case expresses a regional distinctiveness (Anderson 1997; Pojadzińska 2007). Nonetheless, the sense of distinctiveness does not feature a habitual nonreflexivity, but, as is shown by the responses of the residents, features an ideological reflexivity (Nowicka \& Wrona 2015: 22).

The aforementioned notion of heritage defined by Kirshenblatt-Gimblett, captures the reflexive nature of cultural participation, in addition to the phenomenon of the transvaluation of the obsolete (Kirshenblatt-Gimblett 1995: 369). The empirical fact that the focus has shifted from real memory to historical memory, or from culture to heritage, should motivate researchers to change their views on the symbiotic subculture that used to be called peasant culture. Whether the term was (and is) legitimate in terms of its definition and scope is an entirely different, theoretical challenge that this article is too brief to address (Fatyga \& Michalski 2014). More importantly, the formerly clear boundaries that existed between peasant culture and other types of culture, including national culture, are disappearing. This is leading to changes in all cases of cultural localism: namely, syncretisation, heterogenisation, modernisation and, as Arjun Appadurai (2005) points out, subjugation to global trends and visions. On the other hand, the fact that many researchers still define peasant culture through the categories of distinctiveness, homogeneity, indigeneity and primordialism is a symptom of the infamous, colonising approach that draws from the categories of the centre/periphery. The inadequacy of this highly mythologised and ideological cognitive approach can be seen in the statements made by the representatives of the local culture themselves, who make conscious value judgments and show a considerable amount of reflexivity.

The full recognition of these changes will help to remove the exoticising and hibernating approach to the world from the perspective of the putative centre. This approach is especially strong thanks to local activists, tourists and some researchers, who still tend to hypostatise a particular imaginary model of culture that belongs to the periphery, despite the warnings issued some time ago by Robotycki and Węglarz, and recently by Appadurai. Appadurai encourages researchers to forgo the 'pessimist anthropology' that accompanies this approach. Pessimist anthropology tends to look back and to focus on cultural forms that will pass, and can even be said to be somewhat imprisoned in the historicising discourse, in which (in Polish literature, for instance) expressions such as "used to be practised" or "it was believed" - referring to the already historical notion of culture that still aspires to be canon - are overused. On the other hand, Appadurai suggests work- 


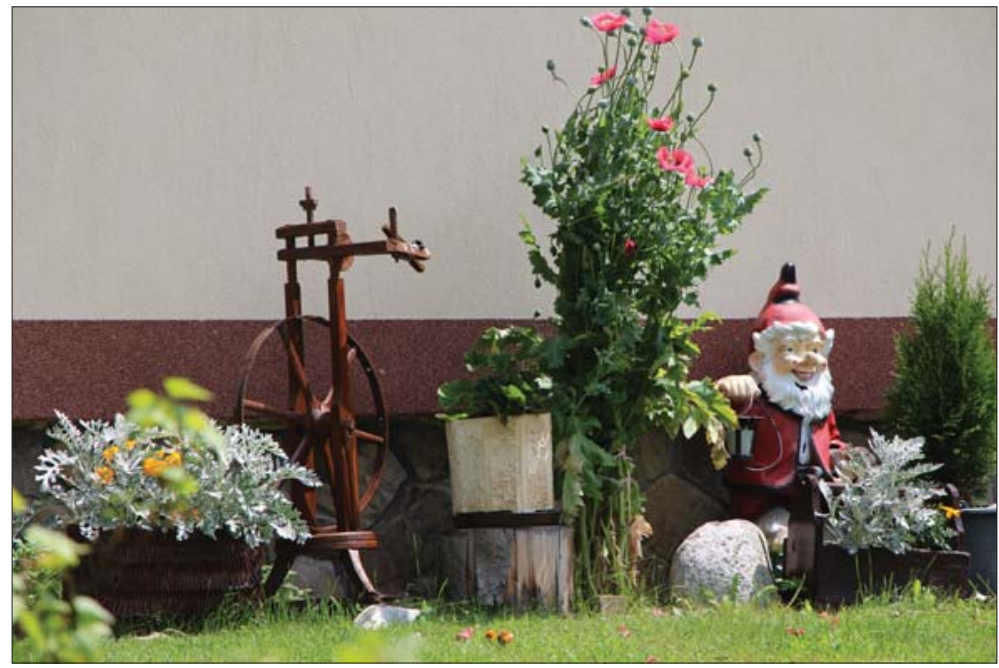

Figure 7.

Author: Janusz Barański

ing on a new model that is termed 'optimist anthropology', which would focus on what is happening in the present rather than on cultural forms that are passing away. Appadurai calls also calls this model the 'genealogy of the present' (Appadurai 2005: 99) that is described as a syncretic amalgamation of the various aspects of life that stem from the categories of global/local, past/present and elite/ popular.

Another contemporary pillar of anthropology, Paul Rabinow (2008), refers to this focus on the cultural here and now as "emergence". In our case, this refers to a shift of focus within the regional culture of Spisz from the historical, hypostatised, theatrical or even reanimated forms to the phenomena that are noncanonical but are experienced as part of everyday life, rather than merely during festive spectacles. However, this does not mean that these spectacles should be discontinued; instead, the focus is shifted towards finding their current functions and, in fact, the current functions of those humble artefacts, such as the wooden carriage wheels, which are returning to life non-spectacularly, and are experienced in the confines of one's thoughts that go far beyond the artefacts themselves. These peculiar mnemotoposes (Kowalski 2013: 56) will potentially undergo mass phenomena of fundamental importance, such as the sense of a regional identity which was mentioned in the responses from the local residents.

Example 7 (see Figure 7). Let us conclude with a final visual example of rusticity, memory and heritage. In front of a quite modern brick house in Spisz, there stands an old spinning wheel alongside a large, plaster garden gnome who holds a lamp in his hand and wears a red vest and a red cap. Both of these objects are drowning in flowers in this well-kept yard. Note that in order to do metadescriptive justice to this example, we should stress that one of the objects that will remind 
the viewer of the past, the spinning wheel (representing rusticity and heritage) coexists here with a rather contemporary plastic gnome. This contemporaneity should be understood in a special manner, since gnomes and their various incarnations belong to the canonical folklore of the Old World. We refer here not only to the culturally vast presence of these gnomes, but also to the fact that they are mass produced and have relative uniform shapes, colours and styles. Therefore, what do these two objects - one a representative of the past and the other a representative of contemporary mass production (which is often considered as kitsch) - have in common? Even Binkley himself argues, in his work about kitsch objects, that it serves to re-establish bygone things, or to secure a return of ontological security and a sense of integrity and predictability to the world, which manifests itself in the bright, fairy-tale colours, for instance (Binkley 2000: 134). Does the spinning wheel not serve the same function, even though the roots that bind it to the past are brittle and thin, rather than strong and sprawling? Indeed, despite the constantly changing cultural landscapes, the human need for a foundation, permanence and assurance (the origins of which can be found in both the past and the present) remains unchanged. This foundation also consists of the discussed above material remnants of the passing traditional local culture.

\section{Bibliography}

Anderson B.

1997 Wspólnoty wyobrażone. Rozważania o źródłach i rozprzestrzenianiu się nacjonali$z m u$, przeł. S. Amsterdamski, Kraków.

Appadurai A.

2005 Nowoczesność bez granic. Kulturowe wymiary globalizacji, przeł. Z. Pucek, Kraków.

Barański J.

2007 Świat rzeczy: zarys antropologiczny, Kraków.

Binkley S.

2000 Kitsch as a Repetitive System. A Problem for the Theory of Taste Hierarchy, "Journal of Material Culture" 2, p. 131-152.

Buchli V.

2007 Introduction, [in:] The Material Culture Reader, ed. V. Buchli, Oxford, p. 1-22.

Fatyga B., Michalski R. (eds.)

2014 Kultura ludowa: teorie, praktyki, polityki, Warszawa.

Glassie H.

1991 Studying Material Culture Today, [in:] Living in a Material World. Canadian and American Approaches to Material Culture, ed. G.L. Pocius, St John's, p. 253-266.

Graves-Brown P.

2000 Introduction, [in:] Matter, Materiality and Modern Culture, ed. P. Graves-Brown, London, p. 1-9. 


\section{Hoelscher S.}

2003 Making Place, Making Race: Performances of Whiteness in the Jim Crow South, "Annals of the Association of American Geographers", no 3, p. 657-686.

Huyssen A.

1995 Twilight Memories: Marking Time in a Culture of Amnesia, New York.

Kirshenblatt-Gimblett B.

1995 Theorizing Heritage, "Ethnomusicology", no 3, p. 367-380.

2004 From Ethnology to Heritage: The Role of the Museum, to appear in conference proceedings, Marseilles.

Kowalski K.

2013 O istocie dziedzictwa europejskiego - rozważania, Kraków.

Nora P.

1989 Between Memory and History: Les Lieux de Mémoire, "Representations", no 26, p. 7-24.

Nowicka E., Wrona A.

2015 Regionalizm czy nowa etniczność? Wieś podhalańska w XXI wieku, Kraków.

Oxford Living Dictionaries: https://en.oxforddictionaries.com/definition/rustic (access: 28.01 .2016$)$.

Pojadzińska A.

2007 Pamięć jako wartość, [in:] Człowiek wobec wyzwań współczesności. Upadek wartości czy walka o wartość, ed. J. Mazur, A. Małyska, K. Sobstyl, Lublin.

Rabinow P.

2008 Marking Time. On the Anthropology of Contemporary, Princeton.

Robotycki C., Węglarz S.

1983 Chłop potęg jest i basta. O mityzacji kultury ludowej w nauce, "Polska Sztuka Ludowa", no 1-2, p. 3-8.

Schiffer M.B.

1999 The Material Life of Human Beings. Artifacts, Behavior, and Communication, London.

Siemiński T.

2010 "Rajskie ogrody" w ikonosferze wsi kaszubskiej. Synkretyczna forma kultury potocznej, Pruszcz Gdański.

Stasiuk A.

2001 Zima, Wołowiec.

Symotiuk S.

1997 Filozofia i genius loci, Warszawa.

Tambiah S.

1990 Magic, Science and Religion and the Scope of Rationality, Cambridge.

Thompson M.

1979 Rubbish Theory: The Creation and Destruction of Value, Oxford. 